\title{
Science and Technology for Rural Development
}

\author{
Radhika Kapur* \\ Pedagogy and Organizational Culture in Nursery Schools, Delhi University, New Delhi, India \\ *Corresponding Author: Radhika Kapur, Pedagogy and Organizational Culture in Nursery Schools, Delhi University, New Delhi, India.
}

Received: April 08, 2019; Published: October 28, 2019

DOI: 10.31080/ASAG.2019.03.0699

\begin{abstract}
In the case of developing countries, the significance of science and technology for rural development has been recognized to a much greater extent. In rural areas, there have been improvements in various areas such as the livelihood of the people, educational institutions, medical and health care centers, small scale industries, agriculture, sources of energy, water, housing, information technology, space technology, women and employment opportunities. Developments and progress in all these areas have been as a result of utilization of innovative techniques and science. Rural people have understood the benefits of computers and television. In India, agriculture is the main occupation in rural areas and people have become aware of advanced agricultural techniques, irrigation methods, seeds, fertilizers and so forth. In this research paper, the researcher has highlighted science and technology from an Indian perspective, characteristics, examples of appropriate technologies, applications of science and technology, significance of science and technology, and role of science academies. There have been developments in the rural areas but much more awareness and thoughtfulness is required for the further development of the rural areas.

Keywords: Science and Technology; Rural Development; Economic Growth; Poverty Alleviation
\end{abstract}

\section{Introduction}

In the case of developing countries, science and technology can play an important part in bringing about social and economic transformation in our country, especially in rural areas. In the case of development of the rural areas, utilization, protection and enhancement of natural, physical and human resources is essential to make long term improvements in the rural living conditions. The significance of science and technology is recognized, it also makes provision of jobs and income opportunities for the rural people while maintaining and protecting the environment of the rural areas. There has been an increasing interest in rural development, the main reason being, systematic effort is necessary to create better living conditions within the rural areas where the vast majority of the populations of the developing countries reside [1].

There have been major objectives of rural development; to improve the living conditions by providing food, shelter clothing, employment and education, to enhance productivity in rural areas and to eliminate poverty, it involves people in planning and development through their participation in decision making and through decentralization of administration and to ensure justice and equal opportunities to the rural population [1]. To meet these objectives, it is vital to recognize the significance of science and technology.

Science and technology: An Indian perspective

After India achieved its independence in 1947, during the first three decades, there was extremely less economic growth within the country only at about $3 \%$, but there was an increase in the in- frastructural facilities for science and technology. In later decades and particularly during the commencement of the 21st century, there have been developments, improvements and introduction of innovative scientific techniques within the country. Science and technology has not experienced the improvements as compared to the business and the industrial sectors. The systems of science and technology are experiencing crisis situations and setbacks, public sector science and technology systems are facing major predicaments. Income generation within the country through the science and technology services have led to greater prosperity for the educated middle class people, in most cases, in the area of information technology [2].

In India, most of the development has taken place through science and technological factors; technical factors have a major role to play particularly in the development of rural areas. Within the rural areas, there have been various sectors such as the agriculture, small-scale industries, houses, dwellings, buildings, medical facilities, education system, offices and so forth. For the purpose of developing these sectors, it is vital that significance of science and technology should be realized. It is only through science and technology that major improvements can be made. There was development of science departments in the central government; these included the departments of science and technology, biotechnology, non-conventional energy sources, ocean development, scientific and industrial research and space. In most cases, rural people are dependent upon the water bodies, and lakes that are nearby their rural areas, therefore, it is vital to ensure that water is utilized for effective purposes and their development should be implemented 
in a safe and secure manner. It is up to the rural people to keep the water bodies clean and not deposit any kind of waste into them.

\section{Significance of science and technology}

Science and technology have been regarded to be significant aspects with concern to rural areas; they are connected with development because they have had a past record of bringing about development in the lifestyle, health conditions, income generation and enhancement of productivity in the lives of the people. Science and technology have been considered to be the main ingredients to solutions to the most severe problems faced by the people in rural areas; these are poverty alleviation and economic challenges [3].

Poverty has been considered to be the most serious problem faced by the rural people, in order to bring about solutions to the problems of poverty, there have been advances in science and technology for the welfare of the rural people. The main areas have been agriculture, health, energy, water and environmental concerns. When science and technological factors have been appropriately utilized in these five areas, then certainly there will be reduction of poverty and people will have more availability of food, health care facilities, sources of energy, clean water and the environmental concerns [3].

Environmental concerns such as air pollution, water pollution, changes in climatic conditions, stratospheric ozone depletion, loss of biological diversity, land degradation and desertification; these changes in the environment can adversely affect the incomes of the poor people who are dependent upon the environment for their livelihood, through air and water pollution human health can also be adversely affected. The key challenge is to recognize that local, regional and global environmental issues are interconnected and affect sustainable development. Therefore, there are synergistic opportunities to develop more effective response options to these environmental issues that enhance benefits, reduce costs, and more sustainably meet human needs. The ability of the countries to adjust and alleviate can be enhanced when environmental policies are integrated with national development policies [3].

For economic growth, science and technological factors are important. First, since the industrial revolution, rich as well as developed countries have had the most science and technical capacity and have grown at an increasing pace. From 1870 to the present, scientifically and technologically advanced countries have become increasingly prosperous, and their rates of growth have not diminished as this took place. Second, enhancement in research and development have been implemented in a consistently positive manner and high across virtually all the fields and the industries that have been taken into account, in the developed and the developing countries. Third, source of income is a must for rural people; they would like to have some kind of employment so that they can earn a living for themselves and their families, generation of income has been considered to be essential for economic growth and science and technological factors have contributed in the generation of employment opportunities for the rural people not only in agriculture, but in also other areas such as industries, offices, educational institutions and so forth.

\section{Science and technology: schemes and programs}

The rural development is determined by the efficient, scientific and optimum assessment, conservation, utilization and distribution of rural resources. Science and technology and rural development are thus inter-related and inter-dependent. In the field of agriculture, advances in agricultural technology have brought about transformations in agricultural productivity. These include the use of high yielding and disease resistant seeds, fertilizers, pesticides, improved implements, irrigation and drainage, crop rotation and cropping patterns, storage, processing and marketing. Various programs connecting science and technology and rural development have been launched in recent times [4]. The major ones have been stated as follows: [4].

1. Science and Society Program of the Department of Science and Technology (DST), the Government of India. It includes $\mathrm{S}$ and $\mathrm{T}$ Application for Rural Development (STARD).

2. S and T Application for the Weaker Sections (STAWS).

3. S and T for Women.

4. S and T for practical and strategic needs of SC Population.

5. Empowering tribal groups through $\mathrm{S}$ and $\mathrm{T}$.

6. Scheme for Young Scientists.

Several other programs are also available for the development of animal husbandry and fisheries, which are an integral part of agriculture in rural India. These include, Dairy Development Program (DDP), Fodder Development Program (FDP), Intensive Cattle Development Program (ICDP) and Special Livestock Production Program (SLPP). Awareness in terms of $S$ and $T$ inputs arising from the researches being done in genetics and breeding, botany, microbiology and biochemistry are made available to all under these programs. The setting up of poultry, piggery, fisheries and sheep production units and rearing of cross-heifers by small and marginal farmers and agricultural laborers are encouraged through these programs. There have been initiation of special programs for the development of hill areas, tribal areas, drought-prone and desert areas, command areas and so forth by adopting area-specific approaches. These are, Hill Area Development Program (HADP), Tribal Development Program (TDP), Intensive Agricultural District Program (IADP), Drought Prone Area Program (DPAP), Desert Development Program (DDP), Command Area Development Program (CADP) and Whole Village Development Program (WVDP) [4].

\section{Characteristics of science and technology}

The methods of science and the culture of technology have to be put into operation in a systematic way. The method of science includes, observation, measurement, recording, classification, comparing with earlier experiences, making hypothesis and testing the hypothesis through new, innovative experiences. The culture of technology should include making note of specifications for material, product and process, performance indices, planning for future and consideration of how to effectively make use of resources, materials, energy and finances. The new developments in Biotechnology, Space Research, Microelectronics, computers and Hi-tech will be of immense benefit to the rural areas [5]. 
The fields of science and technology possess the following characteristics, plans, operations and maintenance, more frequent maintenance is required in the case of technologies, locally available skills; tools and materials are made use of to sustain the technological factors. In the case of rural development, only those kinds of technologies should be used that can be easily managed and repaired. Technologies should be economically sustainable, beneficial and contribute towards a healthy lifestyle of the rural population. Low cost, minimal usage, making the most benefit out of minimal usage should be implemented [6].

\section{Examples of Appropriate Technologies}

The examples of appropriate technologies that have been used in rural development have been stated as follows: [6].

1. Information and Communications Technology: There have been development of computers which are low in cost; they are used in the developing countries. Computers are the technical means that are used on a wide scale, when implementing research in a particular area, internet is used, it is the most comprehensive and appropriate areas to find out information regarding any area, topic, subject or problem.

2. Construction: For the purpose of construction of houses or any buildings; technology is used such as rammed earth, dutch brick, and cob; these materials are generally available and are inexpensive. These construction materials make the houses and the buildings strong, adaptable to all the environmental conditions and well-built. The rural people are able to access these materials in a manageable way so that their construction is carried out in an appropriate manner.

3. Energy: Electricity can be provided from solar cells, wind power or micro, hydro, with energy stored in batteries. Biobutanol, biodiesel, biogas and vegetable oil are considered to be sources of energy. But with transformations taking place, rural areas are also acquiring electricity, as it is necessary to augment one's living conditions.

4. Cooking: Stoves that are smokeless and wood conserving lead to greater efficiency, saves time and labor, reduced deforestation and significant health benefits. In some cases, solar cookers are beneficial depending upon the climatic conditions and the methods of cooking. Research has indicated that individuals in rural areas are making use of electric stoves for the preparation of meals.

5. Health care: In the establishment of health centers, provision of medical facilities, health benefits, there is usage of science and technology. Through the use of technological factors and advancement in the field of science, medicines and innovative machines are coming into existence in hospitals and health care centers in rural areas.

6. Refrigeration: There are certain food items that need to be refrigerated, in rural areas in warm weather conditions, people would like to consume cold water, and hence, there has been provision of pot refrigeration system, which keeps things in cold temperature even without electricity.

7. Television and Radio: These are the technological means that have improved the lives of the rural people; they take pleasure in watching various shows and movies on the television and enjoy listening to the radio. Television and radio systems have become their major sources of entertainment and they even learn various things that they apply in their daily works, for example, programs on the television relating to agriculture benefit the farmers and they apply the appropriate methods in their occupation.

8. Agricultural Technologies: The cultivation of crops such as rice, wheat and maize have been considered to be the major advancement in agricultural technologies. More and more people found employment and there was an immense reduction in poverty; problems of pollution and depletion of land and water got solved through the emergence of technologies.

9. Computers: Research has indicated that individuals in rural areas are making use of computers to augment their understanding in terms of various concepts. Students and youth are the ones, who are making use of computers to a major extent. Through making use of computers, they are not only able to acquire an efficient understanding of the academic concepts, but also are able to work on their tasks and assignments efficiently and communicate. In rural areas, there have been establishment of computer centers, where individuals are able to work on computers well as make use of other technologies, such as, printers and scanners.

10. Mobile Phones: The use of mobile phones is common among rural individuals. The individuals, belonging to various age groups are making use of mobile technology. It is used for various purposes. Research has indicated that rural individuals are not educated. They are either non-literates or possess low literacy skills. They usually make use of mobile phones for communicating and for recreational purposes.

\section{Applications of science and technology}

The main objective of the science and technology applications is to empower the knowledge of the people. It means developing the capability amongst the individuals to achieve their goals and objectives through the generation, acquisition and use of knowledge [1]

- $\quad$ Energy: Energy is essential for agriculture for inputs such as fertilizers, for delivery of water and for transportation. It is also needed to bring about rural industrialization. The single largest source of energy continues to be firewood, and this will continue for quite some time. Therefore, large scale afforestation efforts are called for on scientific lines and involving the rural population to meet their fuel requirements. Biomass generation through the techniques of tissue culture is of great benefit. The non-conventional energy sources which are renewable, decentralized and nonpolluting are particularly relevant to rural areas which are unlikely to obtain electricity for 
their needs for a longtime to come. Biogas plants, smokeless stoves, solar cookers, pumps, solar water pumping systems, solar domestic lighting systems, community lighting and television systems and solar battery charging units are the sources of energy that have led to decentralization of rural industrialization leading to generation of employment and transformation of natural resources into products of higher value.

- Water: Water is the most crucial single resource for the survival of human life. Every effort will have to be made to improve the availability of drinking water in rural areas; it is necessary to devise and implement scientific methods for water harvesting, conservation and recycling. Clean water supply in the rural areas has to be given the highest priority; remote sensing is a powerful technique utilized for water targeting. This effort calls for community participation, technology transfer, evaluation and assessment of existing rural water supply systems, studies on maintenance of water distribution system, development and rehabilitation of springs and use of hydraulic rams for water supply in hilly areas, use of solar energy for rural water supply, development of integrated package for water treatment, to make the water drinkable.

- Housing: Several technologies have been implemented to develop low cost building materials, designs and construction techniques; there has been availability if non-erodible mud plaster for the protection of mud walls from rain.

- Biotechnology: In the field of biotechnology, developments relating to bio-fertilizers, aquaculture, biomass production through tissue culture techniques, embryo-transfer technology to upgrade cattle, herds, etc. have enormous, potential for employment generation and increasing efficiency and productivity for activities in daily life in rural areas; mechanisms to make these effective on a large scale have to be taken into consideration.

- Information Technology: Use of information technology in sectors like agriculture, irrigation, energy, health, family planning, education, employment and transportation are vital for bringing about a major transformation in the rural sector. Information related to local resources, skills and expertise is important to carry out effective decentralized planning. The National Informatics Centre (NIC) was set up in 1975 by the Department of Electronics, it has developed a District Information System, and this established a center in each district of the country. There are a large number of training and information transfer programs which have been based on the nationwide satellite communication network; this will assist in making available valuable information for district and local planning

- Space Technology: There are a wide range of applications of remote sensing technology in areas of disaster warning for coastal fishermen, inland/marine fisheries, minor irrigation, water targeting for drinking water, wasteland identification, vegetation mapping, drought monitoring, etc. Already, with the use of space imagery ground water potential zone maps have been prepared for more than 370 districts which include
91 DPAP districts and 20 DDP districts. A new development relates to the forecast for better fish catches in the coastal regions by making use of the satellite data. It is expected that optimal utilization of space technology can result in better dissemination of information through satellite based communication and broadcasting. This will be of great relevance to remote areas.

- Technology Transfer: In India, there are large number of technologies available, for the effective implementation of the technologies, adequate science and technologies, manpower and infrastructure should be spread throughout the country. What are most urgently called for are proper mechanisms for transfer of technology and an appreciation of what technologies are needed and are appropriate. For this academic institutions, research laboratories, schools and colleges including agricultural medical and engineering institutions and voluntary organizations have all to be brought together through suitable networking. At present, most of the work is fragmented and compartmentalized making the impact much less than the potential.

- Women: Women constitute half of the human resources and today, in India, carry out a very significant part of the farming operations. They are involved in field operations, plantation activities, livestock management, fisheries, sericulture, beekeeping, agriculture, forestry etc. It is essential to organize proper training programs for women and also to devise suitable implements which would reduce drudgery and improve their efficiency and productivity. Women can also be used as most effective disseminators and communicators for simple agricultural and post-harvest technologies and for health care delivery systems. Unless the women are fully associated in the developmental programs, the visible impact of these on society at large would not be felt. It is important that $\mathrm{S}$ and $\mathrm{T}$ relevant to programs is disseminated and implemented as it will have a major multiplier impact.

- Employment: Employment opportunities within the rural areas can be generated with inputs of science and technology in the areas of agricultural practices, animal husbandry, small scale industries, training and skill improvement of the rural people, education, awareness generation and popularization of scientific methods and approaches, biomass cultivation, utilization and agro-processing through innovative biotechnological processes and health care centers.

\section{Role of science academies}

Progress in science, technology and innovation is necessary, although not sufficient to solve the many underlying challenges for sustainable development. These include poor governance at all levels from local to global, inadequate education systems, and lack of rural development (access to roads, financing, education, and empowerment of women). The Academies believe that their own promotion of the values of science, including emphasis on evidence, openness, ethical standards, and social responsibility can contribute to good governance. They acknowledge the context within which science and technology exist and pledge to support policy making for sustainable development by: [7]. 
1. Formulating goals and objectives needed to bring about development.

2. Collaborating with other academies to generate new innovation ideas, knowledge and awareness.

3. Supporting processes to define, monitor and measure the national, regional and international levels progress towards sustainable goals.

4. Policies should be formulated to prevent the adverse effects of science and technologies.

5. Training and supporting the development of human resources in science, technology and innovation.

6. Promoting multidisciplinary research for a holistic approach to sustainable development, including engagement with the private sector.

7. Improving public awareness of the importance of science and technology and how it is useful in rural areas.

8. Promoting mobility of researchers and generation of more and more innovative research methods.

\section{Discussion and Conclusion}

In rural areas, there have been occurrence of problems, the problems of poverty, unemployment, illiteracy and the living conditions of the people are in an underdeveloped state. Scientific approaches, studies, research and innovations are extremely essential to bring about solutions to the problems that are being faced in rural areas. India being a very large country, with diverse geographical and ecological conditions, and varied socio cultural background of the rural population, a standardized prescription or model would be inappropriate for application in all the regions. The prescriptions will have to be location specific, based on the local natural resources, using entirely the skills of the local population to meet their objectives and basic requirements.

In rural areas, the application of science and technology has been in the areas of energy, water, housing, construction, employment generation, information technology, space technology, technology transfer, biotechnology, women and heath care facilities. There have been different kinds of technologies such as information and communications technologies, agricultural technologies, refrigeration, television and radio, cooking, healthcare, construction and energy. It is a fact that science and technologies are the main sources for eradication of poverty and enhancing the livelihoods of the rural people. There has been formulation of goals and objectives by the science academies in order to ensure sustainable development.

Work is required to get initiated towards achieving this objective of applying science in all spheres of rural development. The development of the country will depend upon the development of the rural areas, as it is a fact that $70 \%$ of the country's population resides in rural areas. Through the joint effort of the scientists, administrators and the local people with the complete support of the political organizations and non-governmental voluntary organizations one can successfully achieve the desired goals and objectives. Finally, it can be stated that in order to bring about rural develop- ment in an enhanced manner, the scientists and the researchers perform the key role and they have to continue the breakthrough.

\section{Bibliography}

1. Rai N and Kumar V. "Role of Science and Technology in Making Rural India Shine". IJRDMS 6.1 (2012): 59-72.

2. Narasimha R. "Science, Technology and the Economy: An Indian Perspective". Jawaharlal Nehru Center for Advanced Scientific Research Bangalore (2008).

3. Watson R., et al. "Strategic Approaches to Science and Technology in Development" (2003).

4. Unit 4. Science and Technology for Rural Development. (n.d.)

5. Kalbag SS. (n.d.). Science and Technology for Rural Development.

6. Ananth PN and Karthikeyan M. "Application of Science and Technology in Rural Areas (ASTRA): An Ethiopian Context". Journal of Food and Agriculture Science 4.1 (2014): 1-12.

7. Driving Sustainable Development: the role of Science, Technology and Innovation (2013).

Volume 3 Issue 11 November 2019

(C) All rights are reserved by Radhika Kapur. 